\title{
Los acuerdos de Paz del Teatro Colón y su carácter normativo: una aproximación desde el derecho internacional*
}

\section{The peace agreements of Colón Theatre and normative regulation: an approximation under international law}

\author{
Raúl Fernando Núñez Marín \\ Director de la Maestría en Derechos Humanos y Cultura de Paz \\ de la Pontificia Universidad Javeriana de Cali, Colombia \\ rfnunez@javerianacali.edu.co \\ David Alejandro Claros Hernández \\ Profesor Pontificia Universidad Javeriana de Cali, Colombia \\ daclaros2@gmail.com
}

Recibido: 30/03/17 Aprobado: 17/08/17

DOI: http://dx.doi.org/10.25054/16576799.1552

\section{RESUMEN}

La implementación de los acuerdos de paz evidencia una serie de cuestionamientos de orden jurídico que deben ser abordados desde diversas áreas del derecho. El derecho internacional, en relación con el derecho interno, muestra cómo no todo el texto de los acuerdos alcanzados logra la calificación de acuerdo especial, con base a los postulados de la Convención de Viena sobre Derecho de los Tratados y de la práctica del Derecho Internacional Humanitario y por lo tanto, su inclusión en el bloque de constitucionalidad debe ser parcial y bajo los mecanismos que la propia Corte Constitucional ha establecido en su jurisprudencia.

\section{PALABRAS CLAVE}

Acuerdos Especiales; Acuerdos de Paz; Bloque de Constitucionalidad; Derecho Internacional; Derecho Internacional Humanitario.

\section{ABSTRACT}

The Peace agreements' implementation evidence a variety of legal issues, which must be investigated from various aspects of law. International law, regarding domestic law, demonstrates that the complete text of the reached agreements does not qualify as special agreement. This qualification is based on the postulates of the Vienna Convention on the Law of Treaties and the practice of International Humanitarian Law. Therefore, its inclusion in the constitutionality block must be partial and must be under the mechanisms that the Constitutional Court has established in its jurisprudence.

\section{KEYWORDS}

Constitutionality Block; International Humanitarian Law; International Law; Peace Agreements; Special Agreements.

\footnotetext{
* Artículo de Revisión
} 


\section{INTRODUCCIÓN}

Los acontecimientos recientes en el devenir jurídico colombiano han llevado a que en la academia se presente una interesante discusión sobre la incorporación al ordenamiento jurídico nacional de los acuerdos de paz con las FARC-EP (Fuerzas Armadas Revolucionarias de Colombia - Ejército del Pueblo). Esta discusión implica el análisis de los elementos de una antigua controversia jurídica en el derecho, referida a las relaciones entre el derecho internacional público (DIP) y el derecho constitucional, y a las formas de recepción que los Estados tienen del derecho internacional.

Frente a esto, las iniciativas gubernamentales que se materializan en un acto legislativo implican el reconocimiento de éstos acuerdos como parte del Bloque de Constitucionalidad por disposición del propio acto legislativo; previsión que modifica la práctica emanada del artículo 93 de la Constitución Política de Colombia y de la jurisprudencia de la propia Corte Constitucional colombiana.

Este artículo de revisión, basado en una metodología de carácter hermenéutico-analítico, tiene por objetivo mostrar el estado del arte referido al bloque de constitucionalidad en Colombia y a la recepción del Derecho Internacional, y cómo esto influye en la posibilidad de materializar los acuerdos de paz como normas supraconstitucionales, constitucionales 0 infraconstitucionales.

Así mismo, se deja en claro desde este punto que el análisis se realizará en relación a los acuerdos de paz suscritos en el Teatro Colón y no frente a toda la normativa "derivada" de éstos acuerdos, a saber: los actos legislativos, leyes y decretos reglamentarios que se han emitido, puesto que estas disposiciones se ciñen al carácter normativo que la propia Constitución les otorga y no existe discusión sobre su carácter vinculante y normativo en el ordenamiento jurídico colombiano. Pese a esto, en el análisis final de los acuerdos, se incluirán algunas disposiciones de éstas normas que reflejan y confirman la posición de los autores sobre su inclusión en los acuerdos especiales.

\section{TEORIZANDO SOBRE LOS ACUERDOS}

\subsection{Naturaleza de la expresión 'acuerdo'}

Para comenzar el análisis, de manera introductoria, es menester referirse al concepto de 'acuerdo' en el derecho internacional general. Para tal efecto se abordará, desde las fuentes del derecho internacional, las distinciones que se han hecho respecto de este concepto, haciendo principal énfasis en la interpretación de la Convención de Viena sobre Derecho de los Tratados (en adelante CVDT) que han realizado tanto los ius-publicistas como la jurisprudencia más relevante.

\subsection{Definición de la Convención de Viena de 1969}

La CVDT no provee en general una definición específica de 'acuerdo internacional', pues hace referencia a este en dos aspectos específicos: primero como parte de la definición de 'tratado' (art. 2) y segundo para referirse a aquellos instrumentos internacionales que no están regulados por ésta Convención por no cumplir con sus formalidades 0 por estar suscritos con sujetos del derecho internacional distintos a los Estados (art. 3).

De aquí podría deducirse que la CVDT le otorga a los acuerdos internacionales un carácter de género y a los tratados internacionales un carácter de especie. De igual manera, algunos doctrinantes han manifestado que la CVDT establece una definición amplia y una definición restringida respecto del 'tratado', asimilando en cierta forma a los Acuerdos Internacionales en sentido estricto con la definición amplia (Travieso, J. 2012).

De igual forma, la serie de tratados de Naciones Unidas reconoce que el término 'acuerdo' puede ser usado en tres sentidos: un sentido genérico, que es el del artículo 3 de la CVDT; un sentido particular, que se refiere a acuerdos propios del derecho internacional económico y por último, en el sentido del Derecho de la Integración Regional, ámbito en el cual se suele utilizar ésta terminología. Al respecto, en su libro International Law, Shaw (2008) manifiesta que otros tipos de acuerdos que no están estrictamente incluidos en el artículo 2 de la Convención de Viena, no pierden su carácter internacional y su validez, tales como muchos acuerdos comerciales internacionales que son realizados con diferentes sujetos del derecho internacional (Shaw, M. 2008, p. 114). 


\section{ANÁLISIS HISTÓRICO DE LOS 'ACUERDOS' EN EL DERECHO INTERNACIONAL PÚBLICO}

Al no existir en el Tratado una claridad respecto del sentido del término, es necesario remitirse a los tratados preparatorios de la CVDT. Es así como se encontró el proyecto comentado de la Comisión de Derecho Internacional (CDI) de 1967, en el cual se manifiesta que el proyecto que finalmente se convirtió en Convención decidió eliminar la posibilidad de suscribir tratados con otros sujetos del derecho internacional (especialmente las organizaciones internacionales) debido a las múltiples especificidades que estos tendrían, pero decidió mantenerles su estatus internacional y sus efectos; mediante la reserva del artículo 3, la CDI lo manifiesta en estos términos:

4) La Comisión consideró no menos indispensable impedir cualquier equívoco que pudiera ocasionar la limitación expresa del proyecto de artículos a los tratados celebrados entre Estados o la supresión de las referencias a los tratados de "otros sujetos de derecho internacional" y de las "organizaciones internacionales". En consecuencia, decidió subrayar en el presente comentario que no ha de interpretarse la supresión de esas referencias como reflejo de un cambio de opinión de la Comisión en cuanto a la índole jurídica de esas formas de acuerdos internacionales. Decidió además agregar al artículo 3 (antiguo artículo 2) una reserva específica con respecto a su valor jurídico y a las normas que les son aplicables. (Naciones Unidas, 1967).

Así mismo, en el comentario al artículo 2 manifiesta con más claridad:

5) El vocablo "tratado", tal como se emplea en el proyecto de artículos, se refiere únicamente a los acuerdos internacionales celebrados entre "Estados". El hecho de que aquí se defina así y se emplee en este sentido a lo largo de los artículos no implica, como ya se subraya en el comentario al artículo anterior, la intención de negar a otros sujetos de derecho internacional, como las organizaciones internacionales y las colectividades insurgentes, la capacidad para celebrar tratados. (Subrayado por fuera del texto) (Naciones Unidas, 1967).

Puede observarse entonces, con claridad meridiana, que la intención de la comunidad internacional en su conjunto fue la de mantener la vigencia en materia de efectos de acuerdos internacionales donde una de las partes sean las colectividades insurgentes. Al respecto, más adelante se explicará cómo el concepto de insurgencia se modifica a través del tiempo, específicamente en el Protocolo 2 adicional a los Convenios de Ginebra, hacia el concepto de 'grupos armados'.

Sin embargo, ésta postura no está libre de oposiciones. $\mathrm{Si}$ bien es cierto que el Derecho Internacional Humanitario (en adelante DIH), le ha reconocido cierto estatus a los grupos armados en el Protocolo 1 adicional, dándoles la oportunidad de realizar una declaración unilateral ${ }^{1}$ de sometimiento a sus reglas (especialmente dirigida a los movimientos de liberación nacional) bajo la cual se les otorgan ciertos derechos y obligaciones (Plattner, 1985, p. 299), el Derecho Internacional Público no les otorga ningún derecho especial, lo cual puede observarse en el ius ad bellum y en el ius contra bellum. Al respecto, la doctrina ha expresado que en un derecho de carácter estatocéntrico es necesario incluir a los grupos armados como un nuevo sujeto que expliquen la naturaleza de la relación entre el ius ad bellum y el ius in bello; esto plantea una desigualdad en el estatus jurídico de los grupos armados en las relaciones emanadas del DIH (Dabbone, Z. 2011, p. 395).

\subsection{Desarrollo conceptual: Los acuerdos espe- ciales a la luz del Derecho Internacional Humanitario}

Los acuerdos especiales tal como sostiene Neff, S. (2010), son herramientas específicas del Derecho Internacional Humanitario, cuyo objetivo radica en la ampliación de las obligaciones en cabeza de las partes en el marco de un conflicto armado, ya sea de carácter internacional 0 no internacional, así como en la concertación de ciertos puntos relevantes al desarrollo de las hostilidades. Su origen es consuetudinario, y se remonta a comienzos del siglo XIX donde fueron empleados fundamentalmente para el intercambio de prisioneros de guerra ente los bandos y el pacto de treguas 0 armisticios.

De tal suerte, fueron consagrados en las convenciones de Ginebra de 1864, 1906 y 1929, como herramientas a disposición de las partes para acordar mecanismos de retorno de los heridos y enfermos a sus Estados de

1 - La doctrina ha entendido que más que un treaty making power (capacidad para celebrar acuerdos internacionales), aquí se está frente a un acto unilateral de un sujeto, parecido a lo que se denomina en el DIP un 'Acte Condition'. Cfr. Georges Abi-Saab, 'Les sources du droit international: essai de déconstruction', in Le droit international dans un monde en mutation. Liber Amicorum en hommage au Professeur Eduardo Jiménez de Arechaga, Vol. I, Fundación, Montevideo, 1994, pp. 38-39. 
origen. En ese sentido, su desarrollo gravitó exclusivamente en el plano interestatal, limitándose su aplicabilidad a los conflictos armados de carácter internacional.

No obstante, tras la entrada en vigor de los Convenios de Ginebra de 1949, se hizo referencia expresa a los acuerdos especiales en dos disposiciones diferentes: en el artículo 3 común, como una herramienta para la entrada en vigencia de obligaciones adicionales en materia de DIH en el marco de los conflictos armados de carácter no internacional; y en el artículo 6 común $(7 \mathrm{del}$ Convenio IV), como una posibilidad de las partes contratantes en conflicto para ponerse de acuerdo respecto de ciertos puntos relacionados con el desarrollo de las hostilidades.

Frente a este punto, Barbosa, F. (2017) concluyó respecto al valor del pacto general de paz firmado en el Teatro Colón, que éste adquiere la connotación de acuerdo especial conforme al $\mathrm{DIH}$, sustentado en ambas disposiciones, a saber: el artículo 3 común a los convenios de ginebra de 1949 y artículo 6 del Convenio III promulgado el mismo año. Sin embargo, su principal diferencia bajo su concepto se esgrima en que los denominados 'acuerdos especiales' del artículo 6 buscan mantener o mejorar el estatus de los prisioneros de guerra, mientras que los del artículo 3 común, protegen en general las víctimas de un conflicto armado interno; situación que se analizará a continuación.

\subsection{Los acuerdos especiales alcanzados en el caso colombiano, analizados bajo lo consagrado en el artículo 3 común a los Convenios de Ginebra de 1949}

En línea con lo anterior, se sostiene que sin lugar a dudas los acuerdos alcanzados con el grupo armado "FARC-EP", contenidos en el "Nuevo acuerdo para la terminación del conflicto y la construcción de una paz estable y duradera", corresponden a acuerdos especiales en el marco del artículo 3 común a los Convenios de Ginebra de 1949, y sometidos a las precisas limitaciones que ellos entrañan. Esto, en virtud de los argumentos que se expondrán a continuación.

1. La existencia de un conflicto armado de carácter no internacional en el territorio colombiano ya ha sido ampliamente reconocido a nivel nacional tanto por la jurisprudencia de los altos tribunales, como por el mismo gobierno. Debe precisarse que el reconocimiento de ésta situación fáctica no equivale a la adquisición de beligerancia por parte de cualquiera de los actores en el conflicto según el artículo 3 común.

2. Los acuerdos se encuentran en la delicada esfera de competencia que desarrolla el artículo 3 común. El Comité Internacional de la Cruz Roja ha entendido que los acuerdos de paz, las treguas o los ceses al fuego, pueden estar comprendidos entre los acuerdos especiales en el marco de dicha disposición, solo en la medida que desarrollen o pongan en práctica alguna de las disposiciones contenidas en los Convenios de Ginebra de 1949, o que reconozcan -siempre de una manera más garantista al ser humano- normas de DIH consuetudinario; el cumplimiento de esto, se analizará en un acápite posterior del presente (Comité Internacional de la Cruz Roja [CICR], 2016).

3. Los acuerdos fueron negociados de buena fe por las partes en conflicto, y cristalizados en documentos escritos que brindan certeza sobre el alcance de las obligaciones en cabeza de cada una de las partes.

Como corolario de lo anterior, debe enfatizarse entonces que al cumplirse los requisitos establecidos en el artículo 3 común a los Convenios de Ginebra, se dotan los acuerdos del carácter especial. De hecho, tal como sostiene Barbosa, F. (2017), gran parte de las disposiciones del acuerdo son de naturaleza humanitaria, entendiendo por humanitario no solo lo que es de la esencia misma del ius in bello sino también la complementariedad en el marco de conflictos y posconflictos del DIH con los DDHH y, por ello, poner punto final al conflicto de ésta manera; bajo su apreciación protege el postacuerdo, dado que la firma de la paz con las FARC desarrollará aspectos humanitarios innegables, propios de una "Lex pacificatoria" como la invocada por la profesora Bell, C. (2014).

\subsection{Caracterización de los acuerdos especiales en el derecho interno}

Hasta el momento, se ha demostrado que los acuerdos alcanzados entre el grupo armado "FARC-EP" y el gobierno nacional llenan los requisitos del DIH para ser considerados acuerdos especiales en los términos del artículo 3 común a los Convenios de Ginebra de 1949. En este apartado se explicarán los posibles escenarios que la caracterización como acuerdos especiales puede tener en el plano del derecho nacional, y las perspectivas 
de incorporación de los mismos al bloque de constitucionalidad.

\subsubsection{Los acuerdos especiales considerados como "tratados internacionales entre sujetos del derecho internacional"}

En este acápite se analizarán las dos posiciones existentes en los debates jurídicos contemporáneos frente a la personalidad jurídica de los grupos armados bajo el derecho internacional. En un primer acápite se estudiará la postura que les otorga capacidad para ser sujetos y luego las visiones que consideran imposible ésta aseveración.

\subsubsection{Los grupos armados como sujetos del Derecho Internacional. Posibilidad de considerar como 'tratado' a los Acuerdos de Paz del Teatro Colón} La doctrina y la jurisprudencia clásica han entendido a los Estados como los sujetos plenos del derecho internacional, facultados para adquirir derechos y contraer obligaciones en el plano internacional. No obstante, el avance de las relaciones internacionales y el desarrollo progresivo del derecho internacional y en particular del Derecho Internacional de los Derechos Humanos y del Derecho Internacional Humanitario, ha decantado en una ampliación y flexibilización de los conceptos clásicos de esta rama del derecho. Así, la posición predominante en la actualidad, considera al derecho internacional como un proceso dinámico de toma de decisiones donde se ven envueltos multitud de participantes.

Lo anterior se ve con especial claridad en el marco del DIH, pues su aplicabilidad no se encuentra limitada a las relaciones interestatales, sino que proyecta sus efectos sobre los individuos y otra serie de actores no estatales, entre los que cobran especial relevancia los grupos armados insurgentes. En ese sentido, las normas en materia de $\mathrm{DIH}$ generan obligaciones erga omnes de protección sobre la población civil y de quienes se encuentran hors de combat, sobre las cuales existe un interés legítimo, tanto de los Estados como de los grupos armados (CICR, 2016) en los conflictos armados de carácter no internacional, de garantizar su efectividad (Tribunal Penal Internacional para Yugoslavia, 1999).

Sobre el papel que desempeñan los grupos armados en los conflictos armados de carácter no internacional, y su posibilidad de suscribir acuerdos especiales en el marco del artículo 3 común a los Convenios de Ginebra de 1949, ya se ha referido la Corte Constitucional en oportunidades anteriores.

En la sentencia C-225/95, ésta honorable Corte sostuvo que:

El artículo $3^{\circ}$ común señala que las partes en conflicto podrán realizar acuerdos especiales con el fin de vigorizar la aplicación de las normas humanitarias. Tales acuerdos no son, en sentido estricto, tratados, puesto que no se establecen entre sujetos de derecho internacional público sino entre las partes enfrentadas en un conflicto interno, esto es, entre sujetos de derecho internacional humanitario (CConst, C-225/95, A. Martínez.).

Si bien la posición de la Corte es tajante en afirmar que los acuerdos especiales no son "en estricto sentido" tratados internacionales, debe reconocerse que en el panorama jurídico actual, dicha posición debe ser revalorada a la luz de los nuevos desarrollos del derecho internacional, y en particular por dos razones, a saber: (i) por la naturaleza esencialmente consuetudinaria del DIH, lo que implica su constante desarrollo y expansión en virtud de la práctica material y la opinio juris de las partes en conflicto; $y$, (ii) la consagración constitucional del reconocimiento a los principios del derecho internacional en el artículo 9 de la Carta Política.

Sobre este último punto, cabe decir que, en materia de tratados internacionales, el derecho internacional no se agota en los estrictos términos de la Convención de Viena sobre el Derecho de los Tratados de 1969 tal y como se manifestó en el primer acápite. Afirmar la prevalencia de una noción puramente 'interestatal' de la facultad presidencial de dirigir las relaciones internacionales, y de acordar instrumentos jurídicos de distinta naturaleza en desarrollo de dicha función, sería negar de plano la existencia incluso de los tratados celebrados con las organizaciones internacionales como las Naciones Unidas, pues el alcance de la Convención de Viena sobre el Derecho de los Tratados de 1969 excluye expresamente ésta clase de actos.

Frente al asunto que nos compete, tal y como se manifestó en el primer acápite de este artículo, cabe decir que desde 1962 la Comisión de Derecho Internacional, en los debates relativos a la redacción del proyecto de convención sobre el derecho de los tratados, contempló con claridad la posibilidad de celebrar tratados entre diferentes sujetos del derecho internacional, entre los que reconoció los 'insurgentes' o levantados en armas contra el orden constitucional de un Estado. 


\subsubsection{Falta de capacidad jurídica de los grupos insurgentes para celebrar tratados internacionales.}

Otra de las posturas es aquella desde la cual no pueden considerarse como 'tratados internacionales' acuerdos de paz celebrados entre un Estado y un grupo insurgente por cuanto una de las partes, el grupo insurgente -para el caso colombiano las FARC-EP-, no es considerada como sujeto del derecho internacional, siendo éste, tal como se enunció anteriormente, uno de los requisitos de los tratados internacionales de acuerdo al artículo 2 de la Convención de Viena.

Desde ésta postura se sostienen dos tesis fundamentales para asegurar que, si bien los grupos insurgentes no se encuentran dotados de los elementos suficientes para ser considerados como sujetos plenos del derecho internacional, sí podrían considerarse como sujetos del DIH o también una postura más moderada en donde se les reconoce una personalidad jurídica limitada.

Desde la primera tesis, se concluye que al dotar a los grupos insurgentes de la condición de sujetos del $\mathrm{DIH}$, esto no traería consigo el reconocimiento de personalidad jurídica plena a nivel del derecho internacional (Cassese, A. 1981, p. 416). Desde ésta perspectiva, se ha justificado la calidad de sujetos del DIH desde la denominada doctrina de la jurisdicción legislativa (Moir, L. 2002), bajo la cual a éstos grupos se les aplica las normas del $\mathrm{DIH}$, dado que el Estado en su capacidad de legislar para todos los ciudadanos, ha aceptado dichas normas.

Desde la segunda postura previamente enunciada, aquella que dota y reconoce de personalidad jurídica limitada a los grupos insurgentes, se sostiene que aquellos grupos están obligados a las normas y premisas del DIH en forma independiente al Estado, concluyendo que, así como éstos grupos tienen una serie de deberes y obligaciones derivados de aquellas normas, también deben ser sujetos de algún tipo de reconocimiento de personalidad jurídica. Por esto en ocasión a que los grupos armados, como las FARC-EP, tienen una serie de deberes bajo el DIH, también tendrán una capacidad legal; en consecuencia, se encontrarían provistos de personalidad jurídica, pero ésta personalidad debe advertirse es limitada, ya que sólo les permite ser sujeto de deberes mas no de derechos (Waschefort, G., 2011).
En este sentido, el reconocimiento de la personalidad jurídica a estos sujetos es variable. Autores como Lauterpacht, H. (1970), sostienen que el Estado puede autónomamente reconocer a los grupos armados como sujetos internacionales, en tanto sean titulares de obligaciones de DIH (p. 136-137). Geoffrey Watson a su vez afirma que bajo la practica internacional, ya se le ha reconocido a algunos grupos personalidad jurídica limitada, como ha ocurrido con los movimientos independentistas o de liberación como Mozambique, Guinea-Bissau y Angola, entre otros (Watson, G. 2010). Bajo ésta postura, el autor sostiene que la Organización para la Liberación Palestina -OLP- actuó como sujeto del derecho internacional al firmar los acuerdos de Oslo con el Estado de Israel en 1993.

Sin embargo, esta postura ha sido ampliamente debatida y cuestionada por otros autores como Robbie Sabel, pues en el escenario de los acuerdos de Oslo, la OLP no actuó como sujeto del derecho internacional, por lo que aquellos no tienen la categoría de actos bilaterales en el DI; bajo su tesis, los acuerdos de paz están dotados de valor jurídico bajo el derecho internacional por la actuación de la única parte que tiene personalidad jurídica, siendo ésta el Estado. Esto es posible gracias a una declaración unilateral del Estado, la cual se condiciona al cumplimiento del grupo armado de las obligaciones que le correspondan según los acuerdos (Sabel, R. 2001, p 248-252).

Este punto es especialmente importante en el caso colombiano, ya que Colombia ha sido el único país que en tres momentos diferentes de la historia ${ }^{2}$ ha reconocido beligerancia a grupos armados, incluso grupos extranjeros, lo cual demuestra que la cultura jurídica local ha sido proclive a utilizar figuras del derecho internacional para dotar de capacidad jurídica a grupos armados (Guerrero-Apraiez, V. 2017, p.301).

En conclusión, con las dos posturas anteriormente expuestas, existe absoluto acuerdo en que los Estados tienen plena personalidad jurídica. Sin embargo, existen diferentes visiones sobre el estatus jurídico de los demás intervinientes; es por esto que autores como Christine Bell consideran que los acuerdos de paz con insurgentes no constituyen tratados internacionales en sí mismos aunque, al mismo tiempo, reconocen que estos docu-

2 - Estos tres momentos fueron: 1. En 1870, el Congreso de Colombia promovió el reconocimiento de los insurrectos cubanos frente al Reino de España como beligerantes; 2. En 1979, Colombia lideró los países que reconocieron la beligerancia de los miembros del Frente Sandinista en Nicaragua y 3. En 1999, Colombia reconoció la beligerancia de la misma guerrilla de las FARC ante las negociaciones de San Vicente del Caguán y la existencia de una zona de distensión. 
mentos son fuente especial de derecho internacional (Bell, C. 2006, p. 373). En consonancia con ésta postura, sostiene Barbosa, F. (2017) que el acuerdo especial de paz firmado el 24 de noviembre de 2016 y refrendado el 29 y 30 de noviembre del mismo año, si bien no tiene la naturaleza de tratado internacional, sí es una fuente de derecho internacional.

Ahora bien, bajo cualquiera de las dos posturas anteriormente descritas, ya sea como un tratado internacional (primera postura) o como una fuente especial de derecho internacional (segunda postura), es necesario entender cómo se realizaría la incorporación efectiva de éstas fuentes de derecho internacional al ordenamiento jurídico interno, siendo ésta posible a través de la figura del Bloque de Constitucionalidad, el cual es el siguiente aspecto a analizar.

\section{EL CONCEPTO DE BLOQUE DE CONSTITU- CIONALIDAD COMO ELEMENTO INTEGRADOR DEL ORDENAMIENTO JURÍDICO}

El concepto de Bloque de Constitucionalidad ha sido abordado por distintos autores como Estrada Vélez, quien lo define como "el conjunto de normas que configuran una unidad constitucional que es empleada como parámetro de constitucionalidad de las restantes normas del ordenamiento" (Estrada, V. 2005, p. 79).

La Corte Constitucional definió el Bloque de Constitucionalidad como aquel

...compuesto por aquellas normas y principios que, sin aparecer formalmente en el articulado del texto constitucional, son utilizados como parámetros del control de constitucionalidad de las leyes, por cuanto han sido normativamente integrados a la Constitución, por diversas vías y por mandato de la propia Constitución. Son pues verdaderos principios y reglas de valor constitucional, esto es, son normas situadas en el nivel constitucional, a pesar de que puedan a veces contener mecanismos de reforma, diversos al de las normas del articulado constitucional stricto sensu (CConst, C-225/95, A. Martínez.).

De lo anterior se colige que el Bloque de Constitucionalidad es mucho más amplio que el texto de la Carta Política porque este comprende además de los principios y normas constitucionales, la incorporación de los convenios internacionales de derechos humanos intangibles, e inclusive los instrumentos internacionales que contienen derechos humanos que sí pueden llegar a ser restringidos durante los Estados de Excepción (como por ejemplo el derecho a la libertad de locomoción), pero estos últimos solo constituyen "parámetros de interpretación" de los derechos consagrados en la constitución.

\subsection{Bloque de Constitucionalidad en sentido estricto}

El bloque de constitucionalidad en sentido estricto estaría conformado por: el texto constitucional incluyendo el preámbulo; las convenciones sobre derecho internacional humanitario; los tratados internacionales consagren derechos humanos no susceptibles de ser restringidos, ni siquiera durante los estados de excepción; los instrumentos internacionales sobre DDHH que reconozcan derechos que a su vez estén consagrados en la norma suprema; los tratados limítrofes, teniendo en cuenta lo establecido en la sentencia C-191-98 MP. Eduardo Cifuentes Muñoz; la Ley estatutaria que regula los Estados de Excepción y la doctrina de los tribunales internacionales con respecto de los tratados de derechos humanos, cuya interpretación y desarrollo les ha sido encomendada en determinados casos.

\subsection{Bloque de Constitucionalidad en sentido lato}

El Bloque de Constitucionalidad en sentido lato está compuesto por todas las normas antes referidas en el bloque en estricto sentido; es decir, la constitución incluido el preámbulo; las convenciones sobre derechos humanos intangibles y tangibles, siempre que estos últimos estén consagrados en la carta; las decisiones de los tribunales internacionales encargados de analizar e interpretar las convenciones sobre derechos humanos; la doctrina de los órganos de control de los tratados internacionales sobre derechos humanos; las reglas sobre $\mathrm{DIH}$, adicionándose las leyes estatutarias y las leyes orgánicas. Otros autores como Gutiérrez Beltrán sostienen que el bloque en sentido lato está conformado únicamente por las leyes orgánicas y estatutarias excluyendo de esta clasificación las normas que ostentan "dignidad constitucional" (Gutiérrez, B. 2007, p. 34).

3.3. Los acuerdos especiales no ingresarían de forma automática al bloque de constitucionalidad stricto sensu: aplicación del Principio Pro Persona como criterio de incorporación al Bloque de Constitucionalidad

Este punto suscita una profunda discusión desde la teoría misma del derecho constitucional y de la incorporación 
del derecho internacional al derecho interno. El análisis de ésta cuestión debe partir desde la premisa bajo la cual, la disciplina o práctica de la Corte Constitucional para la inclusión de normas en el Bloque de Constitucionalidad no obedece a una subregla de derecho constitucional ni a una metodología prestablecida (test), sino más bien a una posible arbitrariedad interpretativa bajo un concepto comodín de aplicación del principio pro persona, que como ya se vio, en muchos casos no es realmente aplicado por la Corte.

Habiendo dejado en claro lo anterior, debe entonces observarse que lo que se buscaba por parte del Acto Legislativo 01 de 2016 era modificar esta "técnica" de incorporación del derecho internacional, acercándose a la técnica o fórmula establecida tanto en el derecho argentino como recientemente en el derecho brasilero, de identificar directamente en la Constitución o en la Ley que normas hacen parte del Bloque de Constitucionalidad.

Esto debe afirmarse pese a lo establecido en el vigente artículo transitorio $\mathrm{xx}$, adicionado a la Constitución por el Acto Legislativo 02 de 2017, que reza en su tenor literal:

Artículo transitorio xx. En desarrollo del derecho a la paz, los contenidos del Acuerdo Final para la terminación del conflicto y la construcción de una paz estable y duradera, firmado el día 24 de noviembre de 2016, que correspondan a normas de derecho internacional humanitario o derechos fundamentales definidos en la Constitución Política y aquellos conexos con los anteriores, serán obligatoriamente parámetros de interpretación y referente de desarrollo y validez de las normas y las leyes de implementación y desarrollo del Acuerdo Final, con sujeción a las disposiciones constitucionales (Congreso de la República, 2017).

Si bien este artículo modifica la terminología que se utilizó en el Acuerdo Final y en el Acto legislativo de 2016 en el sentido de no hablar de inclusión en el Bloque de Constitucionalidad, mantiene la idea de considerar el contenido de los acuerdos como parámetro de interpretación de las demás normas, es decir, parámetro de constitucionalidad, que en el fondo implica ser parte del Bloque de Constitucionalidad.

\section{4. ¿IMPLICAN LOS ACUERDOS DE PAZ DEL TEA- TRO COLÓN UNA PROTECCIÓN MÁS AMPLIA DE LOS DERECHOS YARECONOCIDOS?}

Dicho lo anterior, debe afirmarse que la única metodología, o presunta metodología que uno podría extraer de la jurisprudencia de la Corte Constitucional referente a la inclusión de normas en el Bloque de Constitucionalidad en sentido estricto, hace alusión a la aplicación del principio pro persona, razón por la cual ciertos tratados ingresan al bloque y otros no v.gr: CEDAW sí, Belem do Paráno.

Para ello sería necesario identificar dentro de los acuerdos de paz normas que generen una mayor protección a las personas frente a las ya existentes y de esta manera, entenderlas como incluidas en el Bloque de Constitucionalidad; por lo tanto, sería necesario analizar qué normas del nuevo acuerdo sobre el cese al fuego y de hostilidades bilateral y definitivo y dejación de las armas entre el gobierno nacional y las FARC-EP cumplen este requisito.

Debe mencionarse que esta postura no es compartida por autores como Barbosa, F. (2017). Éste sostiene que únicamente los aspectos humanitarios del acuerdo pueden entenderse incorporados de manera automática, por lo tanto son factibles de aplicar de forma directa, incluyendo en ésta clasificación temas como los del desminado, entrega de menores, cese al fuego bilateral y definitivo, dejación de armas, entre otros. Sin embargo, aquellos otros tópicos que bajo su consideración no se encuentran ligados de manera directa con aspectos del $\mathrm{DIH}$, como los cambios en participación política, la incorporación de la jurisdicción de paz, entre otros, deben insertarse a la Constitución para su aplicabilidad a través de actos legislativos y Leyes.

\section{1 ¿Qué normas de los acuerdos de paz podrían ser consideradas como acuerdos especiales en los términos del artículo 3 Común?}

Habiendo llegado a la conclusión de que efectivamente el "Nuevo acuerdo final de paz" del 24 de noviembre de 2016 es un acuerdo especial en los términos del artículo 3 común a los convenios de Ginebra (CICR, s.f., p. 6), es imperativo iniciar el análisis frente a qué normas del mismo podrían ser consideradas como acuerdos especiales, o si por el contrario, todo el acuerdo debe ser considerado en su integralidad como un acuerdo especial.

Frente a lo anterior el CICR en su más reciente actualización de comentarios a los Convenios de Ginebra del año 2016 dispuso que:

10. Un acuerdo de paz, un acuerdo de cese de hostilidades u otro acuerdo también pueden constituir acuerdos espe- 
ciales a los fines del artículo 3 común, o un medio para aplicar ese artículo, si contienen cláusulas para crear otras obligaciones derivadas de los Convenios de Ginebra y/o sus Protocolos adicionales. Al respecto, cabe recordar que los "acuerdos de paz" concluidos con miras a poner término a las hostilidades pueden contener disposiciones derivadas de otros tratados de derecho humanitario, como la concesión de una amnistía a los combatientes que hayan realizado sus operaciones de conformidad con las leyes y costumbres de la guerra, la liberación de todas las personas capturadas o el compromiso de buscar a las personas desaparecidas. Si contienen disposiciones derivadas del derecho humanitario, o si implementan obligaciones del derecho humanitario que ya incumben a las partes, esos acuerdos, o las disposiciones pertinentes, según corresponda, pueden constituir acuerdos especiales conforme al artículo 3 común (CICR, 2016).

Partiendo de ésta base, es necesario iniciar el análisis respectivo de los distintos elementos del nuevo acuerdo, para determinar qué elementos deberían ser o no considerados como acuerdos especiales. Debe advertirse, sin embargo, que dada la extensión del acuerdo y las limitaciones de espacio del presente escrito, no se podrán abordar todas las temáticas previstas en el mismo, centrándose de manera esencial en el punto 1 del denominado "Acuerdo del Teatro Colon".

Relativo al punto del desarrollo rural integral, se pueden generar diversas interpretaciones acerca de si se desarrollan o no, a través de éste, normas del $\mathrm{DIH}$. Al respecto, hay que recordar que el Comité Internacional de la Cruz Roja -CICR- (2008) ha señalado que las partes pueden incluir en un acuerdo especial nuevas obligaciones jurídicas, que van más allá de las disposiciones del $\mathrm{DIH}$, estableciendo puntos específicos que cobren relevancia y pertinencia en el marco de un conflicto armado en particular.

El escenario de creación de nuevas normas jurídicas ha sido planteado cuando se va más allá de las disposiciones del DIH ya aplicables en las circunstancias específicas (un acuerdo "constitutivo"). Sin embargo, también podrá simplemente retomar el derecho que ya vincula a las partes (un acuerdo "declarativo"). Asimismo, puede limitarse únicamente a ciertas normas específicas que, en el marco de un conflicto en curso, pueden adquirir una pertinencia particular. En este caso, el acuerdo debe establecer claramente que, pese a su alcance limitado, sus disposiciones se aplicarán sin perjuicio de lo dispuesto en las otras normas aplicables que no se mencionan en él (Mack, M. 2008, p. 16).
La anterior definición es fundamental, dado que amplía el margen de acción y aplicación de los denominados "acuerdos especiales", siendo posible de ésta manera que la aplicación de los mismos no se circunscriba única y exclusivamente a temas e instrumentos jurídicos concretos, sino que se abra la posibilidad de realizar acuerdos que no desarrollen aspectos humanitarios (lo cual no necesariamente debe desarrollarse en acuerdos que, como el caso colombiano, no implican crisis humanitaria), siendo éstos los que se definen como acuerdos constitutivos que, en todo caso, no desmejoren el régimen de protección conferido (Pavlovich, G. 2013, p. 51).

En este sentido, podrían denominarse como "acuerdos constitutivos" a manera ejemplificativa, dadas las limitaciones esbozadas anteriormente los siguientes puntos:

\subsection{El derecho al agua en el acuerdo rural}

El acuerdo rural integral en general desarrolla derechos que ya han sido reconocidos por la Constitución Política de Colombia. Sin embargo, es vital hacer hincapié en la positivización de un derecho especial que las comunidades campesinas o rurales no contaban en su haber como lo es el derecho al agua.

Al respecto el punto 1.1.10 establece:

(...) Desarrollará en un plazo no mayor a 2 años un plan de zonificación ambiental que delimite la frontera agrícola y que permita actualizar y de ser necesario ampliar el inventario, y caracterizar el uso de las áreas que deben tener un manejo ambiental especial, tales como: zonas de reserva forestal, zonas de alta biodiversidad, ecosistemas frágiles y estratégicos, cuencas, páramos y humedales y demás fuentes y recursos hídricos, con miras a proteger la biodiversidad y el derecho progresivo al agua de la población, propiciando su uso racional (Estado colombiano y Farc-Ep, 2016, p.19).

Esto resulta sin duda alguna en un reconocimiento oficial del derecho al agua de las comunidades rurales, el cual solo había sido enunciado por la jurisprudencia de la Corte Constitucional de Colombia en sentencias como la T-740 de 2011, donde la Corte reconoce el derecho al agua y el respeto a los medios y formas tradicionales de acceso de las comunidades.

Esto se profundiza aún más en el punto 1.3.1.2 al manifestar:

Infraestructura de riego: con el propósito de impulsar la producción agrícola familiar y la economía campesina en 
general, garantizando el acceso democrático y ambientalmente sostenible al agua, el Gobierno Nacional creará e implementará el Plan Nacional de Riego y Drenaje para la economía campesina, familiar y comunitaria. Para el desarrollo del Plan se tendrán en cuenta los siguientes criterios (...) (Estado y Farc-Ep, 2016, p.24).

Y es aún más evidente cuando reconoce un derecho a la gestión colectiva del agua por parte de las comunidades rurales en el punto 1.3.2.3 al decir:

*La participación activa de las comunidades -hombres y mujeres- en la definición de las soluciones de vivienda y la ejecución de los proyectos. *La asistencia técnica y la promoción de las capacidades organizativas de las comunidades para garantizar el mantenimiento, la operación y la sostenibilidad de las soluciones de acceso al agua y manejo de aguas residuales. *Promover prácticas adecuadas para el uso del agua potable (Estado y FarcEp, 2016, p.27).

Otros puntos como el 1.3.3.1 del acuerdo de Estado y Farc- Ep (2016) reconocen el deber del Estado de garantizar vía el apoyo a las comunidades esta gestión colectiva: "^El apoyo con medidas diferenciales a las organizaciones comunitarias y asociaciones para contribuir a la gestión de proyectos de infraestructura y equipamiento (vías, vivienda, salud, educación, agua y saneamiento básico, riego y drenaje)" (p.28).

Es así como puede concluirse que el acuerdo rural integral sí incluye medidas que desarrollan de mayor forma derechos y por lo tanto, estas normas deben estar incluidas en lo que se considera el acuerdo especial.

\subsection{El derecho a la seguridad en el punto dos del acuerdo}

El derecho a la seguridad es uno de esos derechos de poco desarrollo constitucional, convencional y jurisprudencial, pues su contenido ha sido bastante difuso dependiendo de las circunstancias de cada sociedad. En el caso colombiano, existe jurisprudencia al respecto de líderes sindicales y defensores de derechos humanos que se encuentran en situación de riesgo; por ejemplo, en la sentencia T -224 de 2014 (Corte Constitucional, 2014) haciendo alusión a la sentencia T-339 de 2010 respecto de los riesgos. Algo similar ocurre en el Sistema Interamericano de Derechos Humanos en el caso Yarce contra Colombia.
La mencionada sentencia de la Corte Constitucional define el derecho a la seguridad en los siguientes términos:

La jurisprudencia de esta Corte ha resaltado que la noción de "seguridad" se proyecta en tres dimensiones distintas, a saber: (i) como un valor constitucional, (ii) como un derecho colectivo y (iii) como un derecho fundamental. La Corte ha señalado que el derecho a la seguridad personal no se ciñe únicamente a los eventos en los que esté comprometida la libertad individual (protección de las personas privadas de la libertad), sino que comprende todas aquellas garantías que por cualquier circunstancia pueden verse afectadas y que necesitan protección por parte del Estado; concretamente, la vida y la integridad personal como derechos básicos para la existencia misma de las personas (Corte Constitucional, 2014, p.12).

Pese a esta existencia o desarrollo jurisprudencial, el contenido de este derecho como puede apreciarse ha sido definido en términos de la obligación de garantía del Estado en materia de prevención de riesgos, y no bajo un contenido real del mismo; situación que cambia en el acuerdo 2 de Teatro Colón, que establece en el punto 2.1.2:

Como parte de una concepción moderna, cualitativamente nueva, de la seguridad que, en el marco del fin del conflicto, se funda en el respeto de la dignidad humana, en la promoción y respeto de los derechos humanos y en la defensa de los valores democráticos, en particular en la protección de los derechos y libertades de quienes ejercen la política, especialmente de quienes luego de la terminación de la confrontación armada se transformen en opositoras y opositores políticos y que por tanto deben ser reconocidos y tratados como tales, el Gobierno Nacional establecerá un nuevo Sistema Integral de Seguridad para el Ejercicio de la Política (Estado y Farc-Ep, 2016, p.38).

Este contenido da lugar a la creación de un completo sistema de seguridad que no solo se basa en la prevención, sino en el contenido específico de este derecho que aquí ha sido definido. Además, es un derecho que genera una transversalidad en los acuerdos, pues al mismo tiempo se hace referencia también en el acuerdo 3 en el punto 3.4.4.

Continuando entonces con el análisis planteado, debe entenderse a los acuerdos humanitarios y de paz como mecanismos que en estricto rigor y conforme lo disponen los diversos Convenios de Ginebra, son una institución optativa y bajo ningún supuesto obligatoria, regidos bajo el principio de igualdad, que permiten a las partes de un 
conflicto armado de carácter no internacional, tal como dispone el artículo 3 común a los Convenios de Ginebra de 1949, convenir la vigencia de otras normas del DIH con el propósito de ampliar los marcos de protección.

Bajo esta postura, es dable concluir que este punto haría parte del "Acuerdo Especial"; sin embargo, existen serias críticas y visiones divergentes al anterior planteamiento. Por ejemplo, el uso generalizado de este tipo de acuerdos ha estado circunscrito únicamente hasta la fecha, a normas del DIH, tal como expone Mangas, A. (1990, p. 85). Se ha llegado a señalar que la máxima utilidad que podría dársele a este artículo 3 común, es la ampliación del reconocimiento de prisionero de guerra, aplicable solo en conflictos internacionales, para poder hacer extensible su régimen de protección en conflictos armados internos.

En palabras de la Corte Constitucional de Colombia, al tratar el tema de los acuerdos especiales, se dispuso que:

Sin embargo, parece deseable políticamente que existan esos compromisos recíprocos, ya que de esa manera se asegura una mayor aplicación progresiva de las normas humanitarias del Protocolo II. En tal contexto, la realización de los acuerdos especiales puede fortalecer esos compromisos entre las partes y favorecer la puesta en marcha de mecanismos de verificación, que logren, en la práctica, un creciente cumplimiento de las obligaciones humanitarias por las partes enfrentadas (CConst, C225/95, A. Martínez).

Partiendo de esta interpretación dada por el órgano rector en materia constitucional de Colombia, la materia de los acuerdos se circunscribiría única y exclusivamente a la aplicación de normas humanitarias, más específicamente las del Protocolo II. Debe mencionarse frente a este protocolo, que él mismo busca la protección a las víctimas de los conflictos armados no internacionales, dado que tiende a la disminución de los estragos de la guerra al imponer a las partes enfrentadas obligaciones humanitarias destinadas a preservar a la persona humana en las difíciles condiciones de un conflicto armado no internacional.

Haciendo un análisis histórico de los últimos 30 años sobre los acuerdos especiales suscritos hasta el momento, se puede concluir que los escenarios más recurrentes en donde los encontramos, son en aquellos acuerdos entre un grupo armado no estatal y el Estado contra el cual libra hostilidades, o entre dos grupos armados no estatales que luchan entre ellos. Un claro ejemplo de éstos, fueron los acuerdos establecidos entre Croacia y la República Federal de Yugoslavia en 1990, con el objetivo de poner en vigor una cantidad importante de disposiciones de los Convenios de Ginebra y otras disposiciones de los protocolos adicionales (Jakovl, J. 1991). También se encuentra el Acuerdo de Intercambio Humanitario entre las Fuerzas Armadas Revolucionarias de Colombia (FARC) y el Gobierno de Colombia, concluido en 2001, que permitió la liberación de 358 soldados y policías retenidos por esa guerrilla a cambio de 14 subversivos, procesados por la justicia colombiana (Acuerdo de Intercambio Humanitario Gobierno- FARC, 2001); el Acuerdo Humanitario de Cese al fuego sobre el Conflicto en Darfur, concluido el 8 de abril de 2004; frente a este acuerdo debe mencionarse que el carácter de 'Acuerdo Especial', única y exclusivamente se le circunscribió al acuerdo de cese al fuego, el acuerdo final que incluyó entre otros puntos:

Mantener separadas sus fuerzas armadas, formar una fuerza conjunta para las zonas más controvertidas, establecer autonomía de seis años, celebrar un referéndum de autodeterminación en 2011, reparto equitativo de los beneficios del petróleo, formación de un gobierno de unidad nacional con vicepresidencia ocupada por el SPLA, no aplicar la ley islámica en el sur del país, cada territorio uilizaría su propia bandera (Fisas, V. 2010, p. 12).

También se puede ver el denominado "Código de Conducta para el Cese de las Hostilidades entre el Gobierno de Nepal y el CPN" (maoísta), concluido en 2006; éste nuevamente tuvo por objeto el alto al fuego bilateral temporal, y el Acuerdo Integral sobre el Respeto de los Derechos Humanos y el DIH en Filipinas, concluido en 1998; frente a este último, debe mencionarse que su objeto se limitóa:

(a) Garantizar la protección a los derechos humanos de todos los Filipinos bajo todas las circunstancias, especialmente de los trabajadores, campesinos y demás gente pobre; (b) afirmar y aplicar los principios del derecho internacional humanitario con vistas a proteger a la población civil y a las personas civiles, así como a las personas que no participen directamente 0 que hayan dejado de participar directamente en las hostilidades, incluyendo las personas privadas de libertad por motivos relacionados con el conflicto armado; (c) establecer mecanismos y medidas eficaces para llevar a cabo, monitorear, verificar y asegurar el cumplimiento de las disposiciones de este Acuerdo; y, (d) preparar el camino para los acuerdos generales sobre reformas económicas, 
sociales y políticas que asegurarán la consecución de una paz justa y duradera (Acuerdo Integral sobre el Respeto de los Derechos Humanos y del CICR en Filipinas, 1998, Art. 2).

Frente a este último, ocurrió una situación similar a la presentada en el acuerdo especial en el conflicto de Darfur, en donde única y exclusivamente se dotó del carácter 'especial', en los términos del artículo 3 común a los Convenios de Ginebra, a éstas disposiciones preliminares y no al acuerdo general que incluía, tal como el caso colombiano, una serie de reformas económicas, sociales y políticas.

Por último como casos de experiencias comparadas, también se podría traer a colación el tratamiento jurídico dado en el caso de la Revolución independentista de Argelia, en donde el gobierno provisional de la república consideró que el artículo 3 común era insuficiente y propuso al Gobierno francés un acuerdo especial para proteger a los prisioneros de guerra de los dos bandos, además de ampliar la protección de la población civil, de los heridos y los enfermos; ésto a través de los denominados Acuerdos de Evian. Lo mismo ocurrió en el conflicto en Yemen, donde gracias a la oportuna intervención de los delegados del CICR se logró acordar un acuerdo especial entre la Monarquía y el Gobierno para la aplicación de las disposiciones esenciales de las Convenciones de Ginebra durante los enfrentamientos ocurridos entre 1964 y 1965 (Veuthey, M. 1983).

\section{CONCLUSIONES}

Si bien es cierto que el "Nuevo acuerdo final de paz" desarrolla los preceptos contenidos en el artículo 3 común a los Convenios de Ginebra, la totalidad de los mismos no tratan las disposiciones contenidas en las normas del DIH. Es evidente cómo dentro del acuerdo se hace alusión a obligaciones estatales que van más allá de lo que se conoce como acuerdos constitutivos en el marco de los acuerdos especiales, como por ejemplo el punto referido al tráfico de drogas y muchas de las obligaciones que emanan del punto electoral y de derechos políticos del acuerdo.

Es imperativo que aquellas normas que desarrollan las disposiciones de los Convenios de Ginebra sean entendidas como acuerdos especiales con todas las consecuencias jurídicas previamente analizadas; esto en referencia a asuntos como el cese al fuego y de hostilidades bilaterales y definitivas, la búsqueda de personas desaparecidas y la protección a civiles, entre otras. Debe dejarse planteado también en el escenario, tal como se esgrimió anteriormente, que incluso las disposiciones que no versen directamente con asuntos estrictamente ligados con el $\mathrm{DIH}$, puedan ser considerados también como acuerdos especiales, dado que tal como se demostró, la Corte Constitucional ha aplicado como criterio integrador del Bloque de Constitucionalidad el denominado criterio "pro persona"; sin embargo, esto estará supeditado a la interpretación que realice la Corte Constitucional.

De igual forma, bajo el argumento de que el objetivo de un acuerdo especial sea ampliar el marco de las obligaciones humanitarias impuestas a las partes en conflicto 0 darles mayor efectividad a las obligaciones ya asumidas, tal como expone Frühling, M. (2003, p. 8), no es posible dotar del carácter de acuerdo especial a la totalidad del acuerdo del Teatro Colón; deben incluirse los puntos tratados en el párrafo precedente.

Lo verdaderamente importante es entender que la posición en el ordenamiento jurídico de los acuerdos de paz refleja el compromiso jurídico político que tiene una sociedad con el posconflicto y tiene implicaciones directas en el nivel de eficacia de las normas que se desarrollen en aplicación de lo allí acordado.

Por otra parte, es fundamental que esa posición responda a un criterio jurídico válido y no simplemente a una intención política del gobierno de turno de ubicarlos en esa categoría, pues esta última situación, permite que un nuevo gobierno, menos proclive a lo determinado en los acuerdos, decida eliminar su categorización normativa.

\section{REFERENCIAS BIBLIOGRÁFICAS}

I. Acuerdo de Intercambio Humanitario GobiernoFARC, 2 de junio. (2001).

II. Acuerdo Integral sobre el Respeto de los Derechos Humanos y del CICR en Filipinas. (1998).

III. Bell, C. (2006). Peace Agreements: Their Nature and Legal Status. American Journal of International Law, Vol. 100, p. 373-412.

IV. Barbosa, F. (2017). Justicia Transicional o impunidad. La encrucijada de la paz en Colombia.. 1 ed. Bogota: Ediciones B.

V. Cassese, A. (1981). The Status of Rebels under the 1977 Geneva Protocol on Non-International Armed Conflicts. The International and 
Comparative Law Quarterly 30, No. 2, p. 41639.

VI. CICR. (2016). Actualización de Comentarios a los Convenios de Ginebra. Obtenido de: https://www.icrc.org/es/document/acuerdosespeciales-acuerdos-de-paz-dih-colombiacomentarios-convenios-de-ginebra\#pie1

VII. CICR. (s.f.). 23. CICR, Mejorar el respeto del derecho internacional humanitario en los conflictos armados no internacionales. Obtenido de: https://www.icrc.org/spa/assets/files/ other/icrc_003_0923.pdf

VIII. Comité Internacional de la Cruz Roja [CICR]. (2016). Compilación de Derecho Internacional Humanitario Consuetudinario, Regla No. 144. Recuperado el febrero de 2017, de: https://www.icrc.org/customary-ihl/eng/docs/ v1_rul_rule144. Consultado febrero de 2017

IX. Dabbone, Z. (2011). International Law: Armed Groups in a State Centric System. International Review of Red Cross. ICRC. Geneve. Vol. 93 No. 882.

X. Estrada V., S. (2005). Los Principios Jurídicos y el Bloque de Constitucionalidad. Bogotá: Editorial Procuraduría General de la Nación.

XI. Estado colombiano y Farc-Ep (2016) . Acuerdo Final para la terminación del conflicto y la construcción de una paz estable y duradera. Disponible en:

http://www.altocomisionadoparalapaz.gov.co/ procesos-y-conversaciones/Documentos $\% 20$ compartidos/24-11-2016NuevoAcuerdoFinal. pdf

XII. Fisas, V. (2010). Fisas, Procesos de paz comparados. Recuperado el 2017, de http://escolapau.uab.es/img/qcp/procesos_paz _comparados.pdf

XIII. Frühling, M. (2003). Los derechos humanos, el derecho internacional humanitario, el secuestro y los acuerdos especiales. Estados Unidos: Naciones Unidas, Alto comisionado para los derechos humanos.

XIV. Guerrero-Apraiez, V. (2017). El reconocimiento de la beligerancia. 1 ed. Bogotá, D.C: Pontificia Universidad Javeriana, p.301.

XV. Gutiérrez B, A. (2007). Bloque de Constitucionalidad. Conceptos y Fundamentos . Bogotá: Universidad Externado de Colombia.

XVI. Jakovl, J. (1991). Memorando de Entendimiento sobre la aplicación del DIH entre Croacia y la República Federal Socialista de Yugoslavia.
XVII. Lauterpacht, H. (1970). The subjects of international law. . International law. Being the collected papers of Hersch Lauterpacht Vol. I: The general works, ed. H Lauterpacht, p.136137.

XVIII. Mack, M. (2008). Mejorar el respeto del Derecho Internacional Humanitario en los conflictos armados no internacionales. Ginebra: Comité Internacional de la Cruz Roja - CICR.

XIX. Mangas, A. (1990). Conflictos armados internos y Derecho Internacional Humanitaria. Salamanca, España: 16 Ediciones Universidad de Salamanca.

XX. Moir, L. (2002). The Law of Internal Armed Conflic. Oxford: Oxford University Press.

XXI. Naciones Unidas. ONU. (1967).

XXII. Neff, S. (2010). Prisoners of War in International Law: The Nineteenth Century. En S. Scheipers, Prisoners in War. Oxford: Oxford University Press.

XXIII. Pacheco S., R. (s.f.). Datos Históricos del derecho Internacional humanitario. Unilibre.

XXIV. Pavlovich, G. (2013). El acuerdo especial humanitario frente al derecho internacional humanitario. Justicia Juris, ISSN 1692-8571, Vol. 9. No 1. Enero - Junio, p 51.

XXV. Plattner, D. (1985). La portée juridique des déclarations de respect du droit international humanitaire qui émanent de mouvements en lutte dans un conflit armé. Revue Belge de Droit International, Vol. 18, 1984-1985, p. 299 (ICRC translation).

XXVI. Sabel, R. (2001). Review of Tthe Oslo Accords: International Law and the Israeli-Palestian Peace Agreements. By Geofrrey R. Watson. The American Journal of International Law 95, No. 1, p. 248-52.

XXVII. Shaw, M. (2008). International Law (6 ed.). Cambridge.

XXVIII. Travieso, J. A. (2012). Derecho Internacional Público. Thompson Reuters.

XXIX. Tribunal Penal Internacional para Yugoslavia [TPIY]. (1999). Prosecutor v. Kupreški?.

XXX. Universidad de Antioquia. (s.f.). Los derechos y los deberes en la constitución política del 91. Obtenido de Los derechos y los deberes en la constitución política del 91 . http://docencia. udea.edu.co/derecho/constitucion/derechos_d eberes_constitucion.html

XXXI. Veuthey, M. (1983). Implementation and Enforcement of Humanitarian Law and Human 
Rights Law in Non-Intemational. Armed Conflicts: The Role of the International Committee of the Red Cross. American University Law Review 33 am. U.L.. 83 (19831984). 92.

XXXII. Waschefort, G. (2011). The Pseudo Legal Personality of Non-State Armed Groups. International Law South African Yearbook of International Law 36, p. 226-236. Recuperado el 2017, de https://ssrn.com/abstract=2466126

XXXIII. Watson, G. (2010). The Oslo Accords: International Law and the Israeli-Palestinian Peace Agreements. Oxford: Oxford University Press.

\section{REFERENCIAS COMPLEMENTARIAS}

XXXIV. Claros P., M. (s.f.). Bloque de Constitucionalidad. Obtenido de: http://econstitucional. com/ensayos/Bloque $\% 20 \mathrm{de} \% 20$ Constitucional idad\%20M.\%20Claros.pdf

XXXV. Ferreira C., A. C. (1999). Los Derechos Innominados en Colombia. Reflexiones sobre su origen. Tesis de grado. Derecho Público. (U. S. Arboleda, Ed.) Bogotá: Universidad Sergio Arboleda. Bogotá: Universidad Sergio Arboleda. Recuperado el 2017, de: http://www.usergioarboleda.edu.co/derechopublico/los_derechos_inn

XXXVI. Olano G., H. (s.f.). El Bloque de Constitucionalidad en Colombia. Bogotá.

XXXVII. Ramelli, A. (2004). Sistema de Fuentes del Derecho Internacional Público y " Bloque de Constitucionalidad" en Colombia. México. Obtenido de:

http://www.juridicas.unam.mx/publica/rev/ccon st/cont/11/ard/ard5.htm

XXXVIII. Rueda A., D. (s.f.). El Bloque de Constitucionalidad en el Sistema Colombiano. Obtenido de: https://www.scjn.gob.mx/Transparencia/Lists/ Becarios/Attachments/88/Becarios_088.pdf

\section{REFERENCIAS JURISPRUDENCIALES}

XXXIX. CConst. C-820/06, M. Monroy.

XL. CConst. C-574/92. C. Angarita.

XLI. CConst. C-225/95. A. Martínez.

XLII. CConst. C-191/98. E. Cifuentes.

XLIII. CConst. C-582/99. A. Martínez.

XLIV. CConst. SU-256/99. J. Hernández.

XLV. CConst. SU-563/99. J. Hernández.

XLVI. CConst. C-010/00. A. Martinez.

XLVII. CConst. C-830/01. J.Araujo.

XLVIII. CConst. C-067/03. M. Monroy.

XLIX. CConst. C-401/05. M. Cepeda.

L. $\quad$ CConst. C-228/09. H. Sierra.

LI. CConst. C-442/11. H. Sierra.

LII. CConst. C-400/13. N. Pinilla.

LIII. CConst. T-224/14. J. Palacio 